\title{
Malaria epidemiology in Kobeni department, southeastern Mauritania from 2015 to 2017
}

Sileye Mamadou Diallo 1,2,3, Hervé Bogreau²,3,4, Nasserdine Papa Mze 2,3, Mohamed Salem Ould Ahmedou Salem ', Mohamed Lemine Ould Khairy ${ }^{5,6}$, Philippe Parola ${ }^{2,3}$, Leonardo Basco ${ }^{2,3}$ and Ali Ould Mohamed Salem Boukhary ${ }^{1,2^{*}}$

\begin{abstract}
Background: Plasmodium falciparum malaria is endemic in the southern sahelian zone of Mauritania where intense internal and trans-border human and livestock movement occurs. The risk of importation and spread of drugresistant parasites need to be regularly assessed in this region. The objective of the study was to assess the recent malaria situation near the Mauritania-Mali border.

Methods: Between February 2015 and December 2017, patients with fever or history of fever during the previous $48 \mathrm{~h}$, presenting at the health centre of Kobeni city, were screened for malaria using a rapid diagnostic test (RDT) and microscopic examination of blood smears. The diagnosis was later confirmed by PCR. Cohen's kappa statistics was used to estimate the degree of agreement between diagnostic methods. Fisher's exact test was used to compare proportions. The odds ratio was calculated to measure the association between the use of bed nets and malaria infection.

Results: A total of 2326 febrile patients (mean age, 20.2 years) were screened for malaria. The presence of malaria parasites was detected by RDT and microscopy in $53.0 \%$ and $49.3 \%$ of febrile patients, respectively, and was confirmed by PCR in 59.7\% (45 missing data). Of 1361 PCR-positive samples, 1205 (88.5\%) were P. falciparum, 47 (3.5\%) P. vivax, and 99 (7.3\%) P. falciparum-P. vivax mixed infection. Malaria transmission occurred mostly during and shortly after the rainy season. The annual rainfall was relatively low in $2016(267 \mathrm{~mm})$ and $2017(274 \mathrm{~mm})$, compared to 2015 (448 mm), and coincided with a decline in malaria prevalence in 2016-2017. Although 71.8\% of febrile patients reported to possess at least one bed net in the household in our questionnaire, its reported use was not protective against malaria infection (odds ratio: 1.1, 95\% Cl: 0.91-1.32).

Conclusions: Our study confirmed that $P$. falciparum is the dominant species in the sahelian zone and that malaria transmission is seasonal and associated with rainfall in this zone. The application of the current national policy based on rapid and reliable malaria diagnosis, case management with artemisinin-based combination therapy, intermittent preventive treatment for pregnant women, distribution and use of long-lasting insecticide impregnated bed nets, and the planned introduction of seasonal malaria chemoprevention for all children under 6 years old is expected to sustainably reduce malaria transmission in this zone.
\end{abstract}

Keywords: Plasmodium falciparum, Plasmodium vivax, Drug resistance, Cross-border malaria, Epidemiology, Sahel

\footnotetext{
* Correspondence: alimedsalem@gmail.com

'Unité de Recherche Génomes et milieux (Jeune Equipe Associée à I'Institut

de Recherche pour le Développement [IRD]), Faculté des Sciences et

Techniques, Université de Nouakchott Al-Aasriya, Nouakchott, Mauritania

${ }^{2}$ Aix Marseille Université, IRD, Assistance Publique-Hôpitaux de Marseille

(AP-HM), Service de Santé des Armées (SSA), Vecteurs - Infections Tropicales

et Méditerranéennes (VITROME), Marseille, France

Full list of author information is available at the end of the article
}

(c) The Author(s). 2020 Open Access This article is distributed under the terms of the Creative Commons Attribution 4.0 International License (http://creativecommons.org/licenses/by/4.0/), which permits unrestricted use, distribution, and reproduction in any medium, provided you give appropriate credit to the original author(s) and the source, provide a link to the Creative Commons license, and indicate if changes were made. The Creative Commons Public Domain Dedication waiver (http://creativecommons.org/publicdomain/zero/1.0/) applies to the data made available in this article, unless otherwise stated. 


\section{Background}

Despite decades of control efforts, Plasmodium falciparum malaria is still endemic in southern sahelian zone of Mauritania, as well as in parts of northern Saharan zone where Plasmodium vivax is more common [1-3]. Cases infected with Plasmodium malariae and Plasmodium ovale have rarely been reported in the country [2, 4]. Overall, malaria transmission is seasonal with sporadic outbreaks in Mauritania. Anopheles gambiae sensu lato (s.l.) is the main malaria vector in the country [5-7]. Pyrethroid resistance in Anopheles arabiensis has recently been reported in the Saharan and sahelian zones $[8,9]$.

Nomadic life and internal and trans-border human (i.e., nomadism) and livestock (i.e., transhumance) movement have long been the hallmarks of the sahelian region [10]. Population movement has intensified in recent years due to dynamic regional commercial exchanges, reinforced interdependence between neighboring countries, and construction of paved roads [11]. Moreover, the political instability in Mali, Mauritania's neighboring country to the south, and the resulting inter-ethnic conflicts have led to mass influx of Malian refugees into southern Mauritania $[12,13]$. The sahelian zone, particularly Hodh Elgharbi region, has also become a transit zone for thousands of migrants each year from sub-Saharan Africa on their way to Europe [11, 13]. Population movements increase the risk of importation and spread of malaria parasites, including drug-resistant strains, compromising control efforts and programmes. Because of its longstanding malaria endemicity and proximity to border areas with on-going malaria transmission, Kobeni department in Hodh Elgharbi province could potentially be at the heart of malaria transmission 'hotspots' where disease surveillance needs to be reinforced. Moreover, a better understanding of the dynamics of malaria transmission in this region has become a necessity to ensure malaria containment and elimination from the region. The objective of the present study was to assess and update data on malaria burden and Plasmodium species in Kobeni city, the largest urban city in the sahelian zone near the border with Mali.

\section{Methods}

\section{Study area}

The sahelian region of Mauritania consists of an east-towest belt of steppes and savannah grasslands lying between $150 \mathrm{~mm}$ isohyets to the North (i.e., the southern limit of the Saharan desert) and $500 \mathrm{~mm}$ isohyets to the South (i.e., the northern limit of the Sudanian savannah). It occupies $11 \%$ of the total surface area of Mauritania but has about $61 \%$ of the total population distributed across seven administrative provinces: Trarza, Brakna,
Gorgol, Assaba, Guidimagha, Hodh Elgharbi and Hodh Echarghi [14]. While the population density of the northern Saharan part of Mauritania is about 2.2 persons $/ \mathrm{km}^{2}$, that of the sahelian zone is more than 6 persons $/ \mathrm{km}^{2}$.

Our study was conducted between 2015 and 2017 in the city of Kobeni $\left(15^{\circ} 49^{\prime} \mathrm{N}\right.$; $9^{\circ} 24^{\prime} \mathrm{W}$; altitude above sea level, $200 \mathrm{~m}$ ), an urban city with agropastoral activities, situated at about $18 \mathrm{~km}$ from the border with Mali (Fig. 1). The city of Kobeni is the capital of Kobeni department, one of the four departments of the administrative province of Hodh Elgharbi. Kobeni department is comprised of seven communes, namely El Hassi, Gougui Zemmal, Kobeni, Leghlig, Medbougou, Timizine and El Voulaniya, with a total of 92690 inhabitants among whom 11833 reside in Kobeni city $[15,16]$. Kobeni is at the cross-roads between southeastern Mauritania and Mali. The only existing paved road passing through Kobeni city connects Nouakchott, the capital city of Mauritania, via the 'route de l'Espoir', and Bamako, in Mali, and bifurcates from the town of Nioro, situated near the border with Mauritania, to reach Dakar, Senegal.

The population in Kobeni is mainly composed of Moors, an ethnolinguistic groups that speak a Berberinfluenced Arabic language, and people of black African origin (Pular, also known as Fulani, and Soninke). There are also some minorities belonging to Bambara (the major ethnic group in Mali) and Tuareg ethnic groups. Approximately $49 \%$ of the inhabitants of Kobeni department are living below the poverty line (i.e. less than 1.9 dollars a day) [16]. Subsistence farming and livestock production are the main economic activities in Kobeni department.

The climate in Kobeni is of the sahelian type, characterized by a long dry season from October to June and a short wet season from July to September. The amount of rainfall and its spatial distribution are irregular between years and sometimes even during the same year [17]. Annual rainfall during the study period was 448, 267, and $263 \mathrm{~mm}$ in 2015, 2016 and 2017, respectively (National Office of Meteorology, unpublished data). Temperature data in Kobeni city have not been recorded by the local weather station. The closest meteorological station located in Aioun city, $100 \mathrm{~km}$ to the north of Kobeni, recorded a mean annual temperature of $29.7^{\circ} \mathrm{C}$ (range: $23.6-35.8^{\circ} \mathrm{C}$ ) and the months of May and June as the hottest months [16].

During the study period, the health centre of Kobeni city was the only secondary public health structure in the entire Kobeni department. The medical staff included one general medical practitioner, four nurses, and one laboratory technician. In each commune, there is also a primary health care centre. The nearest public 


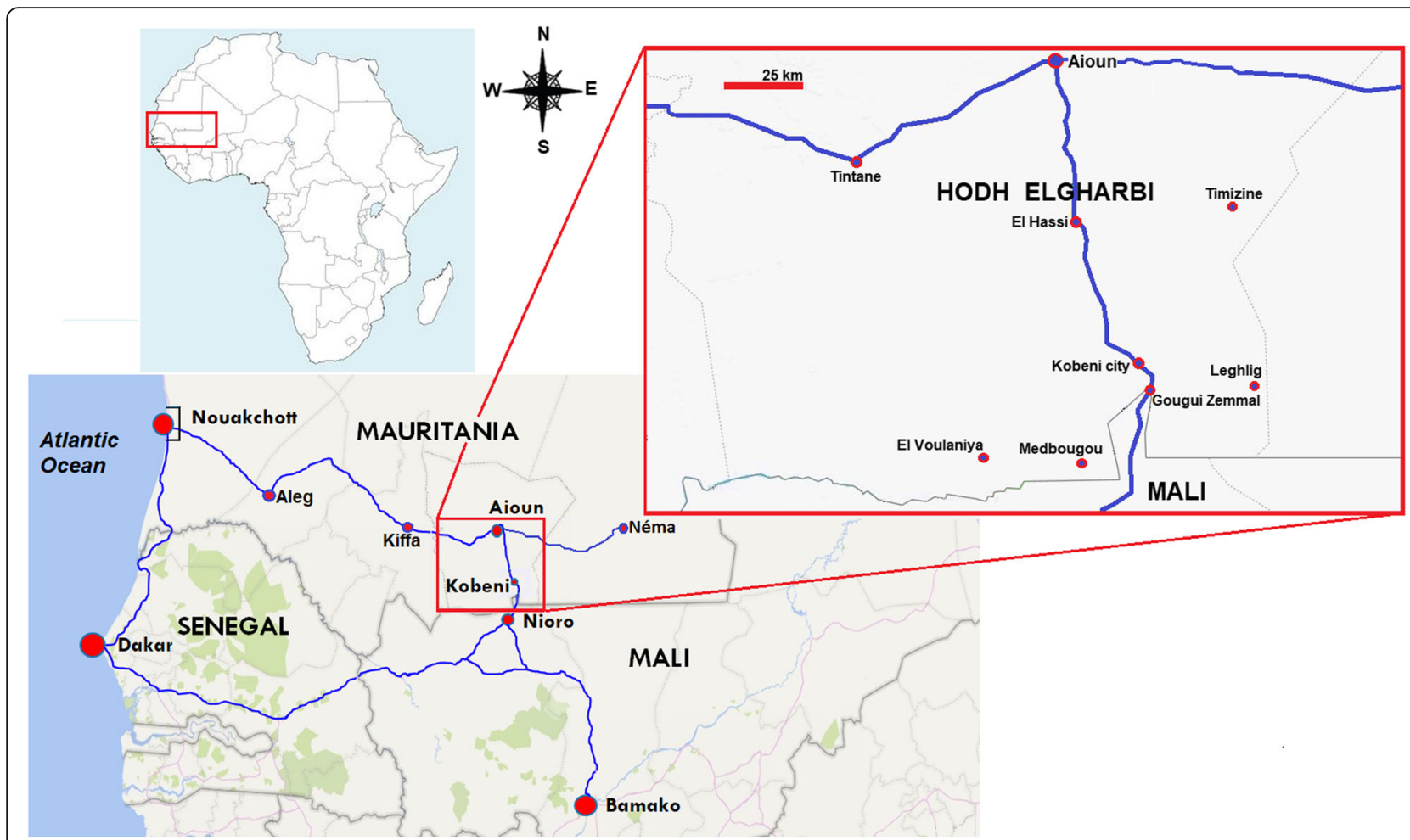

Fig. 1 Map showing the location of Kobeni city. The blue line indicates paved roads. The road connecting Nouakchott and Aioun is part of 'Route de l'Espoir' which continues eastward from Aioun and ends at the city of Néma in southeastern Mauritania

health centre outside Kobeni city is located in Aioun, about $100 \mathrm{~km}$ to the north of the city. This fact largely explains why patients from several localities outside Kobeni city come to the health centre in Kobeni city for medical consultation, particularly during the malaria transmission season.

\section{Study population, inclusion criteria, and sample collection} The study population consisted of patients of all ages consulting the health centre of Kobeni from February 2015 to December 2017. The inclusion criteria of "malaria suspected cases" were fever (a measured axillary temperature of $\geq 37.5^{\circ} \mathrm{C}$ ) at the time of medical consultation or history of fever within $48 \mathrm{~h}$ before consultation, with clinical syndrome suggesting malaria [18]. After obtaining informed consent from the patient (or from the accompanying parents or legal guardians for children), finger-prick capillary blood samples were obtained to prepare thick and thin smears and perform rapid diagnostic test (RDT) for malaria. Capillary blood samples $(100 \mu \mathrm{l})$ were spotted on Whatman 3MM filter paper (GE Healthcare Europe GmbH, Vélizy Villacoublay, France), dried and stored for molecular analysis. During consultation, the patients or the parents (or legal guardians) of febrile children were interviewed to obtain socio-demographic data, including origin, internal and outside recent travel history, and bed net use, and their responses were recorded using a standard, pretested questionnaire.

\section{Rapid diagnostic test}

The Standard Diagnostics (SD) Bioline malaria antigen Pf/Pan test (Standard Diagnostics/Abbott, https://www. abbott.com) was used according to the manufacturer's instructions. This RDT detects $P$. falciparum-specific histidine-rich protein 2 (PfHRP-2) and Plasmodium genus-specific lactate dehydrogenase (pLDH). RDT results were blinded with regards to microscopic examination and PCR results.

\section{Microscopy}

Thick and thin blood films were prepared, stained with 5\% Giemsa solution for $20 \mathrm{~min}$, and examined for the presence of malaria parasites. Thick blood film was considered as negative if no asexual stage of Plasmodium spp. was found after an examination of 100 fields under oil immersion at a magnification of $\times 1000$. Parasite density was determined by counting the number of asexual parasites per 200 leukocytes and assuming a leukocyte count of $8000 / \mu \mathrm{l}$ of blood [19]. The final parasite density was recorded as the average count of two experienced technicians. An experienced microscopist performed quality control by reexamining all positive samples and $10 \%$ of negative blood smears blindly. 


\section{Polymerase chain reaction (PCR)}

Parasite DNA was extracted from dried blood spots using an automated nucleic acid purification system (MagMAX $^{\mathrm{m}}$-Express, Thermo Fisher Scientific, Montigny-le-Bretonneux, France) following the manufacturer's instructions. Plasmodium species was identified using the PCR protocol developed by Snounou et al. (1993) with fluorescent-dye-labeled oligonucleotides [20]. The PCR products were analyzed by capillary electrophoresis.

\section{Statistical analysis}

Data were entered into an Excel spreadsheet (Microsoft Office Excel 2007, Microsoft Corporation, Redmond, WA, USA). Fisher's exact test was used to compare proportions and test association between qualitative variables. Cohen's kappa statistics was used to estimate the degree of agreement between diagnostic methods [2123]. The kappa coefficient was classified as follows: $<0$, no agreement; $0-0.20$, none to slight; $0.21-0.40$, fair; $0.41-0.60$, moderate; $0.61-0.80$, substantial; and $>0.80$, almost perfect agreement. The odd ratios were computed according to Altman (1991) using MedCalc statistical software (MedCalc Software, Ostend, Belgium) [23].
For all statistical tests, the significance level was set at $P$ value $<0.05$.

\section{Results}

\section{Patient characteristics}

Overall, 2326 febrile patients $(n=1247$ in 2015, $n=566$ in 2016, $n=513$ in 2017), mostly composed of Moorish population $(87.7 \%, 2040 / 2326)$, were recruited (Table 1). Other ethno-linguistic groups (Pular, Soninke, Wolof, and Bambara), collectively also known as 'Black Africans,' constituted $12.3 \%(286 / 2326)$ of the patient population. The proportion of females $(53.2 \% ; 1238 / 2326)$ was significantly higher $(P=0.002,95 \% C I: 2.3-10.4 \%)$ than males $(46.8 \%, 1088 / 2326)$ with a female-to-male ratio of 1.14. The mean age was 20.2 years (range, 1 month old to 87 years old), and the median age was 17 years. Children under 5 years old represented 11.1\% (259/2326) of the study population. The mean $( \pm$ standard deviation) axillary temperature at the time of consultation was $38.7^{\circ} \mathrm{C}\left( \pm 1.1^{\circ} \mathrm{C}\right)$.

\section{Malaria prevalence and parasite species}

RDT and microscopy were performed on all recruited patients $(n=2326)$. However, dried blood spots were

Table 1 Characteristics of febrile and malaria-infected patients consulting at Kobeni health centre in Hodh Elgharbi region, southeastern Mauritania, during 2015-2017

\begin{tabular}{|c|c|c|c|c|}
\hline \multirow[t]{2}{*}{ Characteristics } & \multicolumn{4}{|l|}{ Study year } \\
\hline & 2015 & 2016 & 2017 & $2015-2017$ \\
\hline Number & 1247 & 566 & 513 & 2326 \\
\hline \multicolumn{5}{|l|}{ Gender } \\
\hline Female, $n(\%)$ & $640(51.3)$ & $311(54.9)$ & $287(56.0)$ & $1238(53.2)$ \\
\hline Male, $n(\%)$ & $607(48.7)$ & $255(45.1)$ & $226(44.0)$ & $1088(46.8)$ \\
\hline \multicolumn{5}{|l|}{ Age group (year) } \\
\hline$<5, n(\%)$ & $138(11.1)$ & 77 (13.6) & $44(8.6)$ & $259(11.1)$ \\
\hline $5-9, n(\%)$ & $192(15.4)$ & $103(18.2)$ & $67(13.1)$ & $362(15.6)$ \\
\hline $10-14, n(\%)$ & $175(14.0)$ & $82(14.5)$ & $68(13.2)$ & $325(14.0)$ \\
\hline$\geq 15, n(\%)$ & $742(59.5)$ & $304(53.7)$ & $334(65.1)$ & $1380(59.3)$ \\
\hline Mean axillary temperature (range) $\left({ }^{\circ} \mathrm{C}\right)$ & $38.7(37.5-40.9)$ & $38.8(37.5-40.5)$ & $38.6(37.5-40.9)$ & $38.7(37.5-40.9)$ \\
\hline GMPD $^{a}$ (asexual parasites/ $\mu$ l) & 1990 & 1860 & 2640 & 1100 \\
\hline \multicolumn{5}{|l|}{ PCR-positive by age group (years) } \\
\hline$<5, n(\%)$ & $71(9.0)$ & $32(11.2)$ & $22(7.6)$ & $125(9.2)$ \\
\hline $5-9, n(\%)$ & $138(17.6)$ & $53(18.5)$ & $39(13.5)$ & $230(16.9)$ \\
\hline $10-14, n(\%)$ & $113(14.4)$ & $43(15.0)$ & $39(13.5)$ & $195(14.3)$ \\
\hline$\geq 15, n(\%)$ & $464(59.0)$ & $158(55.2)$ & $189(65.4)$ & $811(59.6)$ \\
\hline \multicolumn{5}{|l|}{ Ethno-linguistic groups } \\
\hline Moors $^{b} n(\%)$ & $1101(88.3)$ & $502(88.6)$ & $437(85.1)$ & $2040(87.7)$ \\
\hline Black Africans ${ }^{c} n(\%)$ & $146(11.7)$ & $64(11.4)$ & $76(14.9)$ & $286(12.3)$ \\
\hline
\end{tabular}

${ }^{a}$ Geometric mean of parasite density

${ }^{b}$ Moors refer to ethno-linguistic group speaking Hassaniya, a Berber-influenced Arabic dialect

${ }^{\mathrm{c} B l a c k}$ Africans refer to ethnic groups (Pular [also known as Fulan], Soninke, Wolof and Bambara [the main ethnic group in Mali]) 
available for PCR in 2281 (98.1\%) patients. The prevalence of malaria by RDT, microscopy, and PCR was 53.0\% (1232/2326), 49.3\% (1146/2326), and 59.7\% (1361/ 2281), respectively. Among 1361 PCR-positive cases, 1205 (88.5\%) were due to P. falciparum, 47 (3.5\%) P. vivax, and 99 (7.3\%) P. falciparum-P. vivax mixed infections (Table 2). Few cases $(n=10 ; 0.7 \%)$ of $P$. malariae, either alone or mixed infections, were also observed among PCR-positive samples. The RDT used in the present study did not make a distinction between $P$. falciparum alone and P. falciparum with another Plasmodium species when the 'Pan' band was visible. Using microscopy, almost all smear-positive cases (99.7\%; 1143/1146) were due to $P$. falciparum. The remaining three positive blood samples were diagnosed as $P$. ovale $(0.2 \%)$ or $P$. malariae $(0.1 \%)$. Parasite density varied between 42 to 482000 asexual parasites/ $\mu$ l of blood, with a geometric mean of 1100 asexual parasites/ $\mu$ l of blood. Adults (arbitrarily defined as $>15$ years) were the most affected $(59.6 \%)$, followed by the age group of 5-9 years old $(16.9 \% ; P<0.05)$. Children less than 5 years old were the least affected $(9.2 \% ; P<0.0001)$ (Table 1$)$.

RDT and microscopy results exhibited a substantial agreement (Cohen's kappa coefficient: 0.8; 95\% confidence interval $[C I]: 0.77-0.82)$. However, the comparison of these two diagnostic methods with PCR yielded only a fair agreement between RDT and PCR (Cohen's kappa coefficient: $0.34 ; 95 \%$ CI: $0.30-0.38$ ) and between microscopy and PCR (Cohen's kappa coefficient: 0.30; 95\% CI: 0.27-0.34).

\section{Malaria infection and rainfall patterns}

During the study period, malaria infections occurred mainly between August and November, with a peak in

Table 2 Proportions of malaria-positive tests by diagnostic methods among febrile patients consulting at Kobeni health centre in Hodh Elgharbi region, south-eastern Mauritania, during 2015-2017

\begin{tabular}{lll}
\hline $\begin{array}{l}\text { Plasmodium } \\
\text { spp. }\end{array}$ & \multicolumn{2}{l}{ Number (\%) of patients } \\
\cline { 2 - 3 } Picroscopy & PCR $^{\mathrm{b}}$ \\
\hline P. falciparum (Pf) & $1143(99.7)$ & $1205(88.5)$ \\
P. ovale & 0 & $47(3.5)$ \\
P. malariae (Pm) & $2(0.2)$ & 0 \\
Pf-Pv & $1(0.1)$ & $3(0.2)$ \\
Pf-Pm & 0 & $99(7.3)$ \\
Pf-Pv-Pm & 0 & $6(0.4)$ \\
Pesuls are & 0 & $1(0.07)$
\end{tabular}

${ }^{a}$ Results are expressed as the number of malaria-positive samples and the proportions of malaria species among 1146/2326 (49.3\%) samples that were positive by microscopic examination and $1361 / 2281$ (59.7\%) samples that were positive by PCR

${ }^{\mathrm{b}} \mathrm{PCR}$ was not performed in 45 febrile patients due to the absence of dried blood spots. RDT was positive for $P$. falciparum, with or without other Plasmodium spp., in 1232/2326 (53.0\%)
September or October, corresponding to the unimodal rainfall pattern that characterizes the sahelian climate (July-September) (Fig. 2). During the dry seasons of 2015 and 2016, only $10(0.94 \%)$ malaria cases were diagnosed by PCR. In 2017, patient recruitment was suspended between January and June because of the very low number of malaria cases seen in the two preceding years. The amount of rainfall decreased from $448 \mathrm{~mm}$ in 2015 to $267 \mathrm{~mm}$ in 2016 and $263 \mathrm{~mm}$ in 2017, which coincided with a decline in malaria transmission during the peak season in both 2016 and 2017.

\section{Origin and travel history of malaria-infected patients}

Of 2281 febrile patients for whom PCR was performed, $746(32.7 \%)$ came from outside the commune of Kobeni (Table 3). These patients either were residents of one of the six rural communes of the Department of Kobeni or came from another sub-Saharan African country (Mali, Senegal, Côte d'Ivoire, or Republic of Congo). Based on PCR results, malaria prevalence was 66.1\% (899/1361) among the residents of Kobeni commune, and 33.9\% (462/1361) among those residing outside Kobeni commune.

Among 102 febrile patients with a recent travel history, $31(30.4 \%)$ declared to have travelled to another malaria endemic country in sub-Saharan Africa, and 71 (69.6\%) reported to have travelled to areas in Mauritania known to be endemic for malaria, i.e. zones in southern Mauritania, Nouakchott, or Atar in northern Mauritania. Among these febrile patients with a travel history to endemic areas, 53 (52\%) had PCR-confirmed malaria, including three Malians arriving from their country. Febrile patients without any recent travel history $(n=$ 2179) seeking care at Kobeni health centre were residents in one of the seven communes of the Department of Kobeni. Among these local residents, 1308 (60.0\%) were PCR-positive. No significant difference was found between malaria prevalence among patients with travel history and those with no travel history $(P=0.24)$.

\section{Association between bed net use and malaria infection}

Information on bed net use was obtained from 2281 of 2326 (98.1\%) febrile patients, among whom 1358 (59.5\%) had PCR-confirmed malaria. The proportion of patients who reported to own and use bed nets, either treated or untreated with insecticides (1637/2281, 71.8\%), was significantly higher $(P<0.0001 ; 95 \% C I: 39.3-47.5 \%)$ than those who reported that they do not own or use bed nets (28.9\%) (Table 4). Residents who completed their primary education or went to a Koranic school tended to own and use bed nets more than those who did not complete their primary education $(82 \%$ vs $69 \% ; P<0.05)$. However, the reported use of either insecticide-treated or insecticide-untreated bed nets did not reduce the 


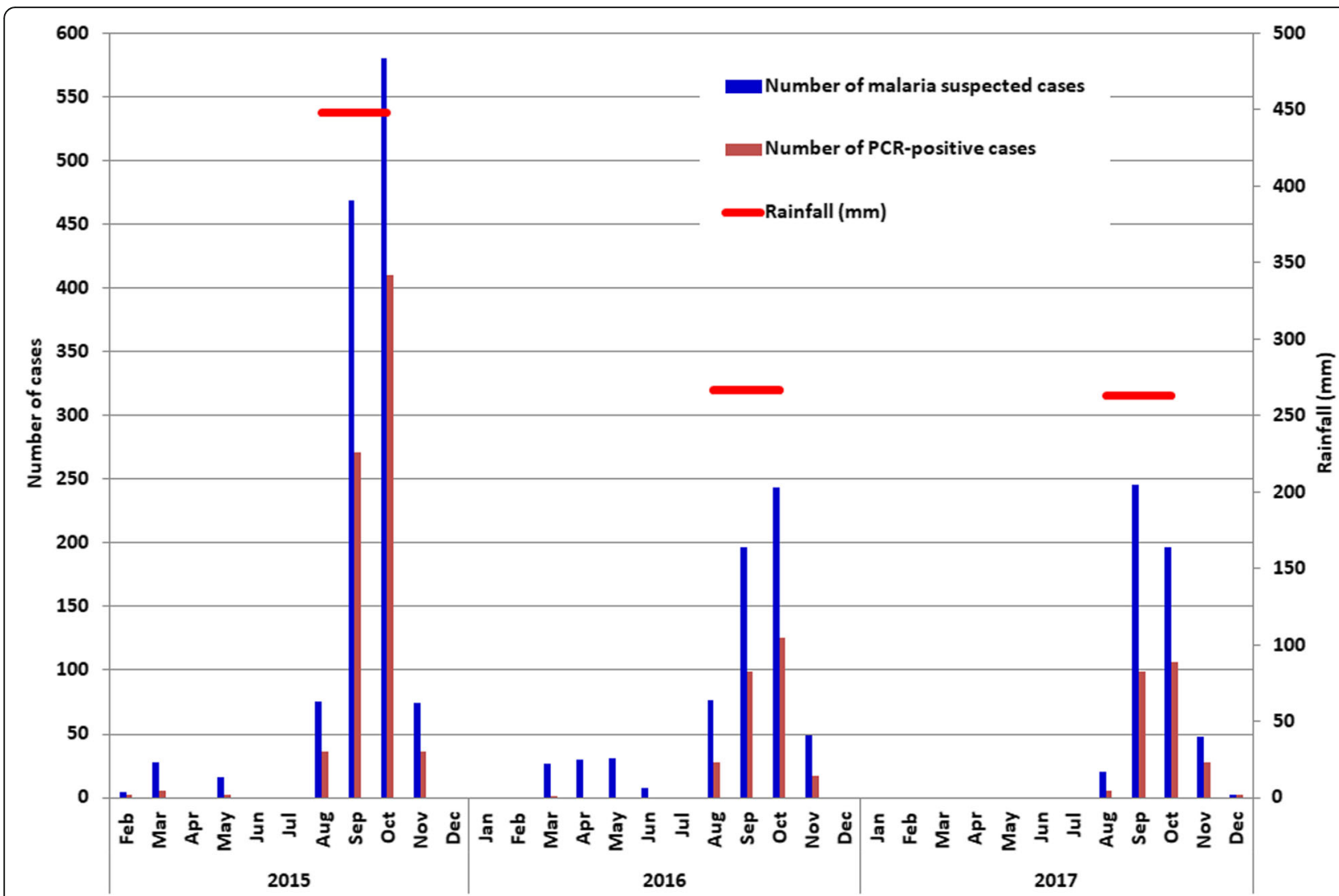

Fig. 2 The number of presumptive malaria cases among febrile patients and number of PCR-positive cases at Kobeni health centre in 2015-2017. The red horizontal bars denote the total annual rainfall and the duration of rainy season for each year. Patients were not recruited during the dry season (January-July) in 2017

probability of being infected by malaria (odds ratio: 1.1 , 95\% CI: 0.91-1.32), as compared to non-use of bed nets $(P>0.05)$.

\section{Clinical manifestation and malaria treatment practice} Of 1232 RDT-confirmed malaria infected patients during 2015-2017, 151 (12.2\%) presented signs and symptoms suggestive of severe malaria: multiple convulsions, lethargy, anuria, jaundice, dark-colored urine, and palmar pallor. The other patients $(1081 ; 87.7 \%)$ presented signs and symptoms of uncomplicated malaria. Quinine salts were the most frequently used antimalarial drug in the health centre of Kobeni to treat confirmed malaria cases, regardless of the clinical manifestations, i.e. either severe or uncomplicated malaria (Table 5). Artesunateamodiaquine or artemether-lumefantrine, antimalarial drugs recommended by the Mauritanian Malaria Control Unit and the WHO to treat uncomplicated malaria, was infrequently used during the study period.

\section{Discussion}

Kobeni is the only sentinel site in Mauritania where studies on malaria epidemiology have been conducted regularly by several research teams over the past 20 years [2, 7, 9, 24-33]. Kobeni is situated within the 'heart' of area of seasonal but intense malaria transmission in Mauritania. Previous parasitological studies in Kobeni were conducted in a limited number of symptomatic children and adults $(n=663)$ in 2009-2010 [2] and asymptomatic children $(n=345)$ in $2011-2013$ [32]. The present study was carried out to update parasitological data in a larger sample $(n=2326)$ of patient population over three consecutive years. The results of the present study showed that $49 \%$ (1146 of 2326) of febrile patients had microscopy-confirmed malaria, mostly due to $P$. falciparum (99.7\%). These results confirm the data of earlier parasitological studies based on microscopy conducted in 2009-2010 in Kobeni in which 57\% (378/ 663) of febrile patients had microscopy-confirmed malaria, of which $96.6 \%$ were due to $P$. falciparum [2]. RDT was introduced in the country in 2010, and PCR was not performed in earlier studies in Kobeni. The comparison of microscopy data in these two studies conducted under similar conditions at the same health centre implies that malaria prevalence remained stable in Kobeni between 2009 and 2017. 
Table 3 Origin, travel history, and malaria positivity among febrile patients consulting at Kobeni health centre in Hodh Elgharbi region, south-eastern Mauritania, during 2015-2017

\begin{tabular}{|c|c|c|}
\hline & \multicolumn{2}{|c|}{ Number (\%) of patients ${ }^{a}$} \\
\hline & Febrile & PCR-positive \\
\hline Origin & $n=2281$ & $n=1361$ \\
\hline From Kobeni commune & $1535(67.3)$ & $899(66.1)$ \\
\hline From outside Kobeni & $746(32.7)$ & $462(33.9)$ \\
\hline Travel history & $n=102$ & $n=53$ \\
\hline External travel ${ }^{b}$ & $31(30.4)$ & $18(34.0)$ \\
\hline Internal travel $^{c}$ & $71(69.6)$ & $35(66.0)$ \\
\hline No travel history outside Kobeni department (commune of residence) & $n=2179$ & $n=1308$ \\
\hline Kobeni city & $1464(67.3)^{d}$ & $864(59.0)^{\mathrm{e}}$ \\
\hline Gougui Zemmal & $168(7.7)^{d}$ & $102(60.7)^{\mathrm{e}}$ \\
\hline El Hassi & $245(11.2)^{d}$ & $150(61.2)^{\mathrm{e}}$ \\
\hline Medbougou & $221(10.1)^{d}$ & $147(66.5)^{\mathrm{e}}$ \\
\hline Leghlig & $29(1.3)^{d}$ & $13(44.8)^{e}$ \\
\hline El Voulaniya & $46(2.1)^{d}$ & $29(63.0)^{e}$ \\
\hline Timizine & $6(0.3)^{d}$ & $3(50.0)^{e}$ \\
\hline
\end{tabular}

${ }^{\text {aPCR }}$ was performed in 2281 febrile patients

${ }^{b}$ From Côte d'Ivoire, Republic of Congo, Mali, or Senegal (3/18 of PCR-confirmed malaria patients were Malians arriving from Mali)

internal travel refers to patients who had travelled to malaria endemic zones in southern Mauritania or to the northern zone where $P$. vivax is known to be endemic (Nouakchott and Atar)

dPercentages of febrile cases without any travel history in each commune (denominator, 2179)

${ }^{\mathrm{e}}$ Malaria infection rate in each commune, defined as the number of PCR-positive malaria cases among febrile cases in each commune

The majority of febrile patients and PCR-positive malaria-infected patients (66-67\%) without any recent travel history were residents of the commune of Kobeni. However, in each commune of the department of Kobeni, malaria infection rates, defined as the number of PCR-confirmed malaria cases among febrile cases, were similar (range: 45-66\%). The presence of semipermanent rain-fed ponds, which allow Anopheles mosquitoes to breed, in Kobeni, Medbougou, and El Hassi communes may be one of the factors that explain high rates of malaria in the study area. Nonetheless, the low coverage of health facilities in the region, particularly in Kobeni department, is another factor that favours the movement of infected patients and probably the propagation of malaria parasites.

Individuals with travel history constitute an additional factor in disseminating malaria parasites. Although the present study did not confirm our initial hypothesis that
Kobeni may be a major site where malaria-infected individuals from different countries transit and possibly spread malaria parasites, there is some evidence to suggest that malaria parasites are not only circulating in and around the commune of Kobeni but also being imported to the commune of Kobeni. Six 'less developed' rural-type communes around the commune of Kobeni are all characterized by high levels of malaria transmission during the rainy season. Malaria prevalence among patients with travel history (52\%) and diagnosed with malaria in Kobeni and malaria prevalence in patients residing in Kobeni who had no travel history $(60 \%)$ did not differ significantly $(P>0.05)$. Most patients reporting a recent travel history visited another malaria endemic area in Mauritania, while others, including a few foreigners, travelled to, or came from, another African country where malaria is known to be endemic and stable. In addition to this known factor, there is an

Table 4 Bed net use and malaria infections among febrile patient consulting at Kobeni health centre in Hodh Elgharbi region, southeastern Mauritania, during 2015-2017

\begin{tabular}{lllll}
\hline $\begin{array}{l}\text { Bed } \\
\text { net } \\
\text { use }\end{array}$ & $N(\%)$ & Number (\%) of patients & & \\
\cline { 3 - 5 } & & Malaria positive & Malaria negative & Odd ratio (95\% Cl) \\
\hline Yes & $1637(71.8)$ & $987(60.3)$ & $650(39.7)$ & $1.1(0.91-1.32)$ \\
No & $644(28.2)$ & $374(58.1)$ & $270(41.9)$ & \\
\hline
\end{tabular}

Information on the use of bed net was available from 2281/2326 (98.1\%) patients. Among those who own bed nets, a large majority of patients reported to have both insecticide-impregnated and non-impregnated bed nets 
Table 5 Antimalarials used to treat malaria infections in patient consulting at Kobeni health center in Hodh Elgharbi region, southeastern Mauritania, during 2015-2017

\begin{tabular}{lllllll}
\hline Year & $N(\%)$ & & & & & \\
\cline { 2 - 7 } & Quinine & ASAQ & AL & SP & CQ & AS-SP \\
\hline 2015 & $703(64.4)$ & $23(1.8)$ & $2(0.2)$ & $27(2.2)$ & $31(2.5)$ & $17(1.4)$ \\
2016 & $296(52.3)$ & 0 & $1(0.2)$ & 0 & $7(1.2)$ & $3(0.5)$ \\
2017 & $284(55.3)$ & 0 & 0 & 0 & 0 & 0 \\
Total & $1283(55.2)$ & $23(1)$ & $3(0.1)$ & $27(1.2)$ & $38(1.6)$ & $65(0.9)$
\end{tabular}

$A S A Q$ Artesunate-amodiaquine, $A L$ Artesunate-lumefantrine, $S P$ Sulfadoxinepyrimethamine, $C Q$ Chloroquine,

AS-SP Artesunate-sulfamethoxypyrazine-pyrimethamine

unknown number of non-residents who get infected with malaria during their transit in Kobeni and are diagnosed once they return home. The real extent of the spread of malaria parasites to and from Kobeni is at present difficult to assess.

A unimodal pattern of malaria transmission characterizes this hotspot with malaria cases occurring mainly during and shortly after the rainy season with a peak in October. This pattern is characteristic of a sahelian zone where rainy season is usually short and irregular. Similar findings have been reported from other sahelian countries, such as Chad [34], Senegal [35], Niger [36], and Mali [37]. Association between malaria infection and the amount of rainfall was also observed in the present study. Indeed, the number of febrile patients who presented at the health centre and the number of patients with confirmed malaria during the transmission season of 2015 (annual rainfall, $448 \mathrm{~mm}$ ) were about twice as high as those of 2016 (rainfall, $267 \mathrm{~mm}$ ) and 2017 (rainfall, $263 \mathrm{~mm}$ ). As expected from previous studies [32], very few malaria cases were observed during the dry season. Of 10 PCR-confirmed malaria cases, 5 were infected with $P$. vivax (1 with mixed $P$. falciparum-P. vivax) and 3 (including 2 with $P$. vivax) had a recent travel history to Nouakchott, where malaria transmission occurs throughout the year [1]. This suggests that many of the laboratory-confirmed malaria infections diagnosed during the dry season in Kobeni were probably due to $P$. vivax relapse and/or malaria imported from elsewhere. No major antimalarial intervention was implemented during this period in the region, with the exception of distribution of bed nets. Compared to 2015, there was a decrease in the number of febrile patients, with or without malaria, in 2016-2017. Based on these observations, it could be reasonably argued that the decrease in the amount of rainfall was probably unfavourable for productive breeding of malaria vectors and therefore for malaria transmission in 2016-2017.

Interventions to control malaria have not been well implemented in Kobeni. This observation is supported by several field observations. First, malaria prevalence has not diminished considerably between 2009 and 2010 and 2015-2017 [2]. Second, data on intermittent preventive treatment in pregnancy are not available. Third, a large majority of malaria-infected patients was treated with quinine, despite the national guideline that recommends artemisinin-based combination therapy (ACT). The efficacy of the first-line ACT, artesunateamodiaquine, has been clinically proven in a study conducted in Kobeni in 2013 [31]. Fourth, although bed nets have been distributed, our study showed that close to one-third of febrile patients did not sleep under bed net. Patients who declared to have used insecticideimpregnated or non-impregnated bed nets were not protected from malaria, as compared to those who declared not to have slept under the bed net. These observations suggest that interventions are either not being implemented in the periphery of the country, in the case of $\mathrm{ACT}$, or are not being properly implemented, in the case of bed nets. Mosquito bed nets, particularly long-lasting insecticide-treated nets (LLINs), have been proven to be highly effective in reducing malaria morbidity and mortality, particularly among children, when properly used $[38,39]$. However, their effectiveness depends on several factors, including the house type and knowledge on the ability of bed nets to prevent malaria (i.e. educational level of the users). For instance, in our study population, the majority of febrile subjects attributed the usefulness of a bed net to the reduction of nuisance caused by mosquitoes rather than its capacity to prevent the bites of infective mosquitoes, to kill mosquitoes when it is insecticide impregnated, and as a consequence, to prevent from being infected by malaria parasites. Moreover, the level of insecticide resistance in Anopheles arabiensis is still very low (deltamethrin, 100\% mortality; permethrin, 98.6\% mortality) in Kobeni [9]. Therefore, there is a need to sensitize households on the sustained use of LLINs in order to optimize their role as an effective malaria control tool.

The earlier study conducted among symptomatic patients in Kobeni did not find any significant trend of malaria prevalence in relation with age groups [2]. In the present study, malaria affected more children between 5 and 9 years old than any other age groups among children. Although this finding may suggest that children of this age group are possibly more exposed to mosquito bites and/or that they have not developed an effective acquired immunity, a convincing explanation with verifiable evidence was not found in this study. Nonetheless, all age groups were affected by $P$. falciparum malaria in Kobeni and a low chemoprevention coverage (1.16\%) among patients was observed. Therefore, interventions should target the most vulnerable populations, i.e. young children and pregnant women, but also older children and adults of all age in Kobeni. In this context, seasonal 
malaria chemoprevention (SMC) could be useful in preventing malaria episodes and associated parasitaemia and anaemia in children under 5 years and even in older children (up to 10 years) in the region [40]. Indeed, SMC was recommended in 2012 by the WHO for children aged 3-59 months living in areas with highly seasonal malaria transmission, as in the Sahelian region in Africa [41]. At present, SMC policy is being implemented in 12 countries in Africa's sahelian sub-region [42], and assessment of its effectiveness in 3.2 million children showed that malaria prevalence was reduced by up to $65 \%$ [43]. In Mali, SMC was reported to reduce malaria infection and disease by more than $80 \%$ in children [44]. The implementation of SMC in Kobeni and surrounding communes needs population sensitization to obtain their active adherence to this novel strategy in Mauritania. Furthermore, as Kobeni is close to the border with Mali, a trans-border collaborative approach is required to control border malaria and counter the threat of spread of drug-resistant malaria.

One of the limitations of the present study is the recruitment of febrile patients in a health centre. Data analysed in the present study do not reflect the malaria situation in the general population in Kobeni in whom asymptomatic carriage of malaria parasites may occur in an unknown proportion of individuals. Studies designed to assess malaria prevalence in the general population would be required to further understand the dynamics of malaria transmission in southern Mauritania. Moreover, since the number of laboratory-confirmed malariainfected patients was very low for two successive dry seasons in 2015 and 2016, patients were not recruited between January and July 2017. It is assumed that 'missing data' during this period in 2017 are similar to those observed in 2015 and 2016. In addition, it is known that malaria prevalence is correlated with the amount of rainfall. In southern Mauritania, the amount of rainfall varies from year to year. Therefore, the epidemiological pattern of malaria observed in Kobeni in 2015-2017 cannot be extrapolated to other time periods and places in southern Mauritania.

\section{Conclusions}

Kobeni is highly endemic for malaria. Transmission is seasonal but intense. Given the context of border malaria, predominance of $P$. falciparum known to be chloroquine- and sulfadoxine-pyrimethamine resistant, and predominance of Anopheles arabiensis, the risk of spread of multidrug-resistant $P$. falciparum strains to other parts of the country and beyond the borders should not be underestimated. The stable level of malaria prevalence in Kobeni over the past 10 years, underuse of ACT, ineffective use or non-use of bed nets seem to be the main underlying causes of the lack of impact of interventions on malaria prevalence and apparent failure of control programme in Kobeni. More parasitological and entomological studies are required to assess malaria burden in this region. Interventions should be further reinforced in Kobeni, for example, by implementing SMC, to limit the risk of spread of malaria.

\begin{abstract}
Abbreviations
ACT: Artemisinin combination therapy; AL: Artesunate lumefantrine; ASAQ: Artesunate amodiaquine; CQ: Chloroquine; GMDP: Geometric mean of parasite density; LLINs: Long lasting insecticide nets; PCR: Polymerase chain reaction; RDT: Rapid diagnostic test; SMC: Seasonal malaria chemoprevention; SP: Sulfadoxine-pyrimethamine
\end{abstract}

\section{Acknowledgements}

The authors wish to express their gratitude to Dr. Aboubecrine Ould Elwafi, Regional representative (Direction Régionale de I'Action Sanitaire, DRASS) of the Ministry of Health in Hodh Elgharbi region, and Dr. Mohamed Limam Ould Dedde, chief doctor of Kobeni health centre, for facilitating the study.

\section{Authors' contributions}

SMD conducted the field study and performed laboratory experiments. $\mathrm{HB}$, NPM, MSOAS supervised the laboratory experiment and analyzed the data. $H B, M L K, P P, L K B, A O M S B$, conceived the study design and drafted and critically revised the manuscript. All authors read and approved the final manuscript.

\section{Funding}

This work was supported by research grants from Expertise France (Initiative $5 \%$ grant). SMD received a Ph.D. scholarship from the French government through the French Embassy in Nouakchott.

\section{Availability of data and materials}

All data generated or analysed during this study are included in this published article.

Ethics approval and consent to participate

This study protocol was reviewed and approved by the institutional ethics committee of the Université de Nouakchott Al-Aasriya and the institutional ethics committee of the Institut de Recherche pour le Développement (IRD), Marseille, France. The purpose of the study was explained in local dialect to adult patients or parents (or legal guardians), who provided informed written consent on behalf of malaria-infected children.

Consent for publication

Not applicable.

\section{Competing interests}

The authors declare that they have no competing interests.

\section{Author details}

'Unité de Recherche Génomes et milieux (Jeune Equipe Associée à I'Institut de Recherche pour le Développement [IRD]), Faculté des Sciences et Techniques, Université de Nouakchott Al-Aasriya, Nouakchott, Mauritania. ${ }^{2}$ Aix Marseille Université, IRD, Assistance Publique-Hôpitaux de Marseille (AP-HM), Service de Santé des Armées (SSA), Vecteurs - Infections Tropicales et Méditerranéennes (VITROME), Marseille, France. ${ }^{3}$ Institut Hospitalo-Universitaire (IHU)-Méditerranée Infection, Marseille, France. ${ }^{4}$ Unité Parasitologie et Entomologie, Département des maladies infectieuses, Institut de Recherche Biomédicale des Armées, Marseille, France. ${ }^{5}$ Ministère de la Santé, Programme National de Lutte contre le Paludisme (PNLP), Nouakchott, Mauritania. ${ }^{6}$ Present Address: Direction régionale de l'action sanitaire, Nouakchott sud, Ministère de la santé, Nouakchott, Mauritania.

Received: 12 August 2019 Accepted: 26 January 2020

Published online: 12 February 2020

\section{References}

1. Ould Ahmedou Salem MS, Mint Lekweiry K, Mint Deida J, Ould Emouh A, Ould Weddady M, Ould Mohamed Salem Boukhary A, et al. Increasing 
prevalence of Plasmodium vivax among febrile patients in Nouakchott, Mauritania. Am J Trop Med Hyg. 2015;92:537-40.

2. Ould Ahmedou Salem MS, Basco LK, Ouldabdellahi M, Mint Lekweiry K, Konate L, Faye $\mathrm{O}$, et al. Malaria-associated morbidity during the rainy season in Saharan and Sahelian zones in Mauritania. Acta Trop. 2015;152:1-7.

3. Deida J, Tahar R, Khalef $Y$, Lekweiry K, Hmeyade A, Khairy M, et al. Oasis malaria, northern Mauritania. Emerg Infect Dis. 2019;25(2):273-80.

4. Cortes H, Morillas-Marquez F, Valero A. Malaria in Mauritania: the first cases of malaria endemic to Nouakchott. Tropical Med Int Health. 2003; 8:297-300.

5. Hamon J, Maffi M, Grenier P, Ouedraogo CS, Djime D. Notes sur les moustiques de la République Islamique de Mauritanie (Diptera: Culicidae) (2e partie). Ann Soc Entomol Fr. 1966;2:371-283.

6. Dia I, Ba H, Ould Mohamed SA, Diallo D, Lo B, Diallo M. Distribution, host preference and infection rates of malaria vectors in Mauritania. Parasit Vectors. 2009;2:61.

7. Mint Lekweiry K, Ould Ahmedou Salem MS, Cotteaux-Lautard C, Jarjaval F, MarinJauffre A, Bogreau $H$, et al. Circumsporozoite protein rates, blood-feeding pattern and frequency of knockdown resistance mutations in Anopheles spp. in two ecological zones of Mauritania. Parasit Vectors. 2016;9:268.

8. Mint Mohamed Lemine A, Ould Lemrabott MA, Niang EA, Basco L, Bogreau $\mathrm{H}$, Faye $\mathrm{O}$, et al. Pyrethroid resistance in the major malaria vector Anopheles arabiensis in Nouakchott, Mauritania. Parasit Vectors. 2017;10:35.

9. Ould Lemrabott MA, Ould Ahmedou Salem MS, Ould Brahim K, Brengues C, Rossignol M, Belghyti D. Seasonal abundance, blood meal sources and insecticide susceptibility in major anopheline malaria vectors from southern Mauritania. Parasit Vectors. 2018;11:232.

10. Apolloni A, Nicolas G, Coste C, El Mamy AB, Yahya B, El Arbi AS, et al. Towards the description of livestock mobility in Sahelian Africa: some results from a survey in Mauritania. PLoS One. 2018;13(1):e0191565 https://doi.org/ 10.1371/journal.pone.0191565.

11. Choplin A, Lombard J. "Suivre la route". Mobilités et échanges entre Mali, Mauritanie et Sénégal. EchoGéo. 2010;14:2-19. https://doi.org/10.4000/ echogeo.12127.

12. Mint Lekweiry K, Ould Ahmedou Salem MS, Basco L, Briolant S, Hafid JE, Ould Mohamed Salem Boukhary A. Malaria in Mauritania: retrospective and prospective overview. Malar J. 2015;14:100.

13. United Nations Children's Fund. Mauritania: Migration profiles. https://esa.un. org/miggmgprofiles/indicators/files/Mauritania.pdf. Accessed 29 Jan 2020.

14. United Nation Framework Convention on Climate Changes. Mauritania Third National Communication to the UNFCCC. 2014. https://unfccc.int/ resource/docs/natc/mrtnc3.pdf. Accessed 7 Apr 2019.

15. Office National des statistiques. Annuaire statistique 2016. Ministère de l'Economie et des Finances, Mauritania. http://www.ons.mr/images/Archive/ doc/publication/Annuaire_Statistique_2016.pdf. Accessed 29 June 2019.

16. Silly G. Etude sur la consolidation des diagnostics de la Wilaya au Hodh Elgharbi. Report (final version). European Union/Islamic Republic of Mauritania. RIMRAP, editors. p. 60. http://www.rim-rural.org/archives/6932. Accessed 29 June 2019.

17. Food and Agriculture Organization. Mauritania country profile. 2005. http:// www.fao.org/nr/water/aquastat/countries_regions/mrt/indexfra.stm. Accessed 29 June 2019.

18. World Health Organization. Guidelines for the treatment of malaria. 3rd ed; 2015. https://www.who.int/malaria/publications/atoz/9789241549127/en. Accessed 29 June 2019.

19. World Health Organization. Assessment and monitoring of antimalarial drug efficacy for the treatment of uncomplicated falciparum malaria. 2003. https://www.who.int/malaria/publications/atoz/whohtmrbm200350. Accessed 29 June 2019.

20. Snounou G, Viriyakosol S, Zhu XP, Jarra W, Pinheiro L, do Rosario VE, et al. High sensitivity of detection of human malaria parasites by use of nested polymerase chain reaction amplification. Mol Biochem Parasitol. 1993;61:315-20.

21. Cohen J. A coefficient of agreement for nominal scales. Educ Psychol Meas. 1960;20:27-46. https://doi.org/10.1177/001316446002000104.

22. Fermanian J. Measurement of agreement between 2 judges. Qualitative cases. Rev Epidemiol Sante Publique. 1984;32:140-7.

23. Altman DG. Practical statistics for medical research. London: Chapman and Hall; 1991

24. Jordan S, Jelinek T, Aida AO, Peyerl-Hoffmann G, Heuschkel C, el Valy AO, et al. Population structure of Plasmodium falciparum isolates during an epidemic in southern Mauritania. Tropical Med Int Health. 2001;6(10):761-6.
25. Eberl KJ, Jelinek T, Aida AO, Peyerl-Hoffmann G, Heuschkel C, el Valy AO, et al. Prevalence of polymorphisms in the dihydrofolate reductase and dihydropteroate synthetase genes of Plasmodium falciparum isolates from southern Mauritania. Tropical Med Int Health. 2001;6(10):756-60.

26. Kleinschmidt I, Omumbo J, Briët O, van de Giesen N, Sogoba N, Mensah NK, et al. An empirical malaria distribution map for West Africa. Tropical Med Int Health. 2001;6(10):779-86.

27. Jelinek T, Aida AO, Peyerl-Hoffmann G, Jordan S, Mayor A, Heuschkel C, et al. Diagnostic value of molecular markers in chloroquine-resistant falciparum malaria in southern Mauritania. Am J Trop Med Hyg. 2002;67(5):449-53.

28. Ould Ahmedou Salem MS, Ndiaye M, Ould Abdallahi M, Lekweiry KM, Bogreau $\mathrm{H}$, Konaté $\mathrm{L}$, et al. Polymorphism of the merozoite surface protein-1 block 2 region in Plasmodium falciparum isolates from Mauritania. Malar J. 2014;13:26.

29. Ba H, Duffy CW, Ahouidi AD, Deh YB, Diallo MY, Tandia A, et al. Widespread distribution of Plasmodium vivax malaria in Mauritania on the interface of the Maghreb and West Africa. Malar J. 2016;15:80.

30. Ba H, Ahouidi AD, Duffy CW, Deh YB, Diedhiou C, Tandia A, et al. Evaluation of malaria rapid diagnostic test optimal-IT pLDH along the Plasmodium falciparum distribution limit in Mauritania. Bull Soc Pathol Exot. 2017;1 10:31-7.

31. Ouldabdallahi M, Alew I, Ould Ahmedou Salem MS, Ba MDD, Ould Mohamed Salem Boukhary A, Ould Khairy ML, et al. Efficacy of artesunateamodiaquine for the treatment of acute uncomplicated falciparum malaria in southern Mauritania. Malar J. 2014;13:496

32. Ouldabdallahi MM, Sarr O, Basco LK, Lebatt SM, Lo B, Gaye O. Efficacy of sulfadoxine-pyrimethamine for the treatment of uncomplicated falciparum malaria in southern Mauritania. Méd Santé Trop. 2016:26:297-301.

33. Duffy CW, Ba H, Assefa S, Ahouidi AD, Deh YB, Tandia A, et al. Population genetic structure and adaptation of malaria parasites on the edge of endemic distribution. Mol Ecol. 2017;26(11):2880-94.

34. Othnigué N, Wyss K, Tanner M, Genton B. Urban malaria in the Sahel: prevalence and seasonality of presumptive malaria and parasitaemia at primary care level in Chad. Tropical Med Int Health. 2006;11:204-10.

35. Ndiath MO, Sarr J-B, Gaayeb L, Mazenot C, Sougoufara S, Konate, et al. Low and seasonal malaria transmission in the middle Senegal River basin: identification and characteristics of Anopheles vectors. Parasit Vectors. 2012;5:2.

36. Guillebaud J, Mahamadou A, Zamanka H, Katzelma M, Arzika I, Maman LI, et al. Epidemiology of malaria in an area of seasonal transmission in Niger and implications for the design of a seasonal malaria chemoprevention strategy. Malar J. 2013;12(1):379. https://doi.org/10.1186/1475-2875-12-379.

37. Barry A, Issiaka D, Traore T, Mahamar A, Diarra B, Sagara I, et al. Optimal mode for delivery of seasonal malaria chemoprevention in Ouelessebougou, Mali: a cluster randomized trial. PLoS One. 2018;13(3): e0193296 https://doi.org/10.1371/journal.pone.0193296.

38. Hawley WA, Phillips-Howard PA, ter Kuile FO, Terlouw DJ, Vulule JM, Ombok $M$, et al. Community-wide effects of permethrin-treated bed nets on child mortality and malaria morbidity in western Kenya. Am J Trop Med Hyg. 2003;68(Suppl. 4):121-7.

39. World Health Organization. World malaria report 2015. Geneva: World Health Organization; 2015. www.who.int/malaria. Accessed 29 June 2019.

40. Ndiaye JLA, Ndiaye Y, Ba MS, Faye B, Ndiaye M, Seck A, et al. Seasonal malaria chemoprevention combined with community case management of malaria in children under 10 years of age, over 5 months, in south-east Senegal: a cluster-randomised trial. PLoS Med. 2019;16(3):e1002762.

41. World Health Organization WHO Global Malaria Programme (2012). WHO policy recommendation: seasonal malaria chemoprevention (SMC) for Plasmodium falciparum malaria control in highly seasonal transmission areas of the Sahel sub-region in Africa. 2012. http://www.who.int/malaria/publications/ atoz/who_smc_policy_recommendation/en/. Accessed 29 June 2019.

42. World Health Organization. World malaria report 2018. Geneva: World Health Organization; 2018. www.who.int/malaria. Accessed 29 June 2019.

43. York A. Seasonal malaria chemoprevention in the Sahel. Lancet Infect Dis. 2017:17(6):588.

44. Dicko A, Diallo Al, Tembine I, Dicko Y, Dara N, Sidibe Y, et al. Intermittent preventive treatment of malaria provides substantial protection against malaria in children already protected by an insecticide treated bednet in Mali: a randomized, double-blind, placebo-controlled trial. PLoS Med. 2011;8: 1000407. 